\title{
Warning at emergency room: The role of diagnostic test in acute aortic dissection
}

\author{
Alfonso Lagi* \\ Chief, Department of Emergency, Hospital Villa Donatello, Florence, Italy
}

\begin{abstract}
Background: The aortic diseases are life - threating diseases which ask to be diagnosed and treated as soon as possible. The main thing is to lose no time. In the Emergency Room, the most appropriate investigations should be performed, so that the accurate decisions can be taken.

Methods: We composed a narrative review analysing the most important prospective population studies (1,641 patients) either retrospective studies (over 14,000 patients) and evaluated guidelines in the filed. Both sensibility and specificity and the chances for doing of the diagnostic test were evaluated.

Results: The specificity and sensitivity of the diagnostic tools was evaluated to decide the priority of test to utilize in emergency room. The diagnostic work up is founded on chest pain associated with age, sex, previous diseases, after which some significant signs and symptoms are measured such as aortic valvular regurgitation, pleural or pericardial effusion, syncope, neurological or vascular symptoms. At the end, one set of diagnostic tests confirming the diagnosis are taken into account. It is imaging tests: Computed tomography (CT), Magnetic Resonance Imaging (MRI), and Transoesophageal Echocardiography (TOE) are equally reliable for confirming or excluding the diagnosis of AAD and they are considered as diagnostic gold standard.

Conclusion: The right balance between availability of the test and its diagnostic sensitivity and specificity is the goal of a proper work up. The whole of the prospective and retrospective population-based ascertainment showed that hospital-based registries indicate as diagnostic gold standard test CT scan or Transoesofageal Echocardiography to make as soon as possible in selected population of high risk patients.
\end{abstract}

\section{Key-message}

The aortic diseases are life - threating and time consuming. To take the appropriate diagnostic test, it may be very expensive. Therefore, in the emergency room health workers should rank the high risk clinical conditions and features which select the patients very likely to suffer from Acute Aortic Disease.

\section{Introduction}

The Acute Aortic Syndromes (AAS) are a severe, life threating and time related disease, which ask fast diagnosis and therapy. The common denominator of AAS is disruption of the media layer of the aorta with bleeding within, along the wall of the aorta resulting in separation of the layers of the aorta (dissection), or transmurally through the wall in the case of ruptured of penetrating atherosclerotic ulcer or trauma. They are defined as emergency conditions with similar clinical characteristics involving the aorta: acute aortic dissection (AAD), intramural haematoma, penetrating aortic ulcer, complete rupture of the aorta, traumatic aortic injury, iatrogenic aortic dissection. The clinical progress of patients with AAS is unpredictable. A high level of suspicion is required for early diagnosis and crucial for patient survival. The aim of this manuscript is to rise a red flag for the health workers of emergency room to improve their reaction and conduct in front of AAD which is the common pathology of all AAS $[1,2]$.

\section{Methods}

The intention was to do a narrative review. Prospective and retrospective population-based studies and guidelines on Acute Aortic Diseases were evaluated for a whole of 1,641 and over 14,000 patients respectively. All retrieved articles were screened for eligibility based on title, abstract, and full content. The specificity and sensitivity of the diagnostic tools was evaluated to decide the priority of test to utilize in emergency room. Guidelines on Acute Aortic disease were evaluated in comparison.

\section{Results}

\section{Epidemiology}

Up-to-date data on the epidemiology of AAD is scarce. In the Oxford Vascular study, its incidence is estimated at six per hundred thousand persons per year. This incidence is higher in men than in women and increases with age [3-5].

A review of 464 patients from IRAD reported a mean age at presentation of 63 years, with significant male predominance $(65 \%)$ [5]. The incidence of dissection appears to be increasing, independent of the ageing population, either It may be that two to three times as many patients die from aortic dissection than from ruptured abdominal aortic aneurysm; with an unknown number of patients dying before diagnosis, the true prevalence is not precise.

The most common risk factor but not the most important, associated with AAD is the acute hypertension, observed in $65-75 \%$ of individuals [6-9].

Correspondence to: Alfonso Lagi, Chief, Department of Emergency, Hospital Villa Donatello, Florence, Italy, E-mail: alfonso.lagil@tin.it

Key words: aortic dissection, blood pressure, morbidity/mortality, population studies, risk factors/global assessment

Received: June 06, 2017; Accepted: June 30, 2017; Published: July 03, 2017 
Other risk factors, less frequent but more important, include aortic valve disease, history of cardiac surgery, cigarette smoking, use of intravenous drugs (e.g. cocaine and amphetamines), Marfan syndrome or other connective diseases.

The most common cause of traumatic aortic dissection or rupture is direct blunt chest trauma, by road traffic accidents or deceleration. An autopsy study of road accident fatalities found that $\nabla 20 \%$ of the patients had a ruptured aorta, emphasizing the importance of traumatic rupture of the aorta [10].

\section{Clinic in acute aortic dissection}

Many signs and symptoms can be associated with chest or back pain, that should solicit the attention of physicians.

Chest pain: Chest pain is the most frequent symptom of AAD. Abrupt onset of severe chest and/or back pain is the most typical feature. The pain may be sharp, ripping, tearing, knife-like, and not different from Acute Myocardial Infarction (AMI); the abruptness of its onset is the most specific characteristic $[11,12]$.

The most common site of pain is the chest $(80 \%)$, while back and abdominal pain are experienced in $40 \%$ and $25 \%$ of patients, respectively. Anterior chest pain is more commonly associated with Type A of AAD, whereas patients with Type B dissection present more frequently with pain in the back or abdomen [13]. The pain may migrate from its point of origin to other sites, following the dissection path as it extends through the aorta.

Pain radiating to the neck, throat, and/or jaw may indicate the involvement of the ascending aorta, particularly when associated with murmur of aortic regurgitation, pulse differentials, or signs of tamponade; conversely, pain in the back or abdomen may herald dissection of the descending aorta

\section{Classification}

Acute thoracic aortic dissection can be classified according to either the origin of the intimal tear, it drives decisions regarding surgical $v s$. non-surgical management. The two most commonly used classification schemes are the DeBakey and the Stanford systems. For purposes of classification, the ascending aorta refers to the aorta proximal to the brachiocephalic artery, and the descending aorta refers to the aorta distal to the left subclavian artery.

\section{DeBakey classification}

- Type I: Dissection originates in the ascending aorta and propagates distally to include at least the aortic arch and typically the descending aorta (surgery usually recommended).

- Type II: Dissection originates in and is confined to the ascending aorta (surgery usually recommended).

- Type III: Dissection originates in the descending aorta and propagates most often distally (non-surgical treatment usually recommended).

Type IIIa: Limited to the descending thoracic aorta.

Type IIIb: Extending below the diaphragm.

\section{Stanford classification}

- Type A: All dissections involving the ascending aorta regardless of the site of origin (surgery usually recommended).
- Type B: All dissections that do not involve the ascending aorta (nonsurgical treatment usually recommended). Note that involvement of the aortic arch without involvement of the ascending aorta in the Stanford classification is labelled as Type B.

The dissection can spread from the intimal tear in a anterograde or retrograde fashion, often involving side branches and causing malperfusion syndromes, tamponade, or aortic insufficiency

\section{Aortic regurgitation}

Aortic regurgitation may accompany $40-75 \%$ of cases with Type $\mathrm{A}$ and may be so severe to influence the prognosis [14]. Pericardial tamponade is observed in $20 \%$ of patients with acute Type A [9].

\section{Heart failure}

Registry IRAD data show that this complication occurs within $10 \%$ of cases of AAD and is commonly related to aortic regurgitation [9]. Although more common in Type A, heart failure may also be encountered in patients with Type B, suggesting additional aetiologies of heart failure, such as myocardial ischemia, pre-existing diastolic dysfunction or uncontrolled chronic hypertension.

Hypotension and shock may result from aortic rupture, acute severe aortic regurgitation, extensive myocardial ischemia, cardiac tamponade, pre-existing left ventricular dysfunction, or major blood loss

\section{Pleural effusions}

Smaller pleural effusions may be detected in $15-20 \%$ of patients, with almost equal distribution between Type A and Type B patterns, and are believed to be mainly the result of an inflammatory process. Large pleural effusions resulting from aortic bleeding into the mediastinum and pleural space are rare because these patients usually do not survive up to their arrival at the hospital [15].

\section{Syncope}

Syncope is an important initial symptom, occurring in approximately $15 \%$ of patients with Type A and in $5 \%$ of those presenting with Type B. This feature is associated with an increased risk of in-hospital mortality because it is often related to life-threatening complications, such as cardiac tamponade or supra-aortic vessel dissection.

\section{Neurological symptoms and peripheral vascular diseases}

They may result from cerebral malperfusion, hypotension, distal thromboembolism, or peripheral nerve compression. The frequency of neurological symptoms range from $15-40 \%$, and in half of the case may be transient. Acute paraplegia, due to spinal ischaemia caused by occlusion of spinal arteries may be a serious disease. Radial or femoral pulses may be absent. Cerebral ischemia and acute myocardial infarction may associate with AAD.

Mesenteric ischemia may also result from the involvement of a major arterial orifice in the dissection process. The perfusion disturbance can be intermittent if caused by a dissection flap prolapse, or persistent in cases of obliteration of the organ arterial supply by false lume expansion. Renal failure may be encountered at presentation or during hospital course in up to $20 \%$ of patients with acute Type A and in approximately $10 \%$ of patients with Type B AAD [7]. This may be the result of renal hypoperfusion or infarction, secondary to the involvement of the renal arteries, or may be due to prolonged hypotension 
In conclusion, in order to rank the patients referring to the risk to be affected from AAS it considered low and high - risk referred conditions, pain and examinations features.

Clinical data, useful to assess the a priori probability of AAD, are resumed in table 1.

\section{Laboratory testing}

If $\mathrm{D}$-dimers are elevated, the suspicion of AAD is increased [15-17]. Typically, the level of D-dimers is immediately very high, compared with other disorders in which the D-dimer level increases gradually. D-dimers yielded the highest diagnostic value during the first hour If the D-dimers are negative, Intramural Hematoma $(\mathrm{IH})$ and Penetrating Aortic Ulcer (PAU) may still be present; however, the advantage of the test is the increased alert for the differential diagnosis [15].

\section{Diagnostic imaging}

The target of imaging in AAD is to identify the evidences reported in table 2 [18].

So, it needs to avoid ineffective exams, cause of time consuming, but to use the most sensitive and specific ones. A flowchart for the emergency room has been developed in order to enhance the standardization of decision making in AAS, because survival is strongly related to time. In the diagnostic work-up clinical data are useful to assess the priori probability of AAS.

Computed tomography (CT), Magnetic Resonance Imaging (MRI), and Transoesophageal Echocardiography (TOE) are equally reliable for confirming or excluding the diagnosis of AAD so that they are considered as diagnostic gold standard.

Table 1. Clinical data useful to assess the probability of acute aortic dissection.

\begin{tabular}{|l|l|l|}
\hline High-risk conditions & High-risk pain features & $\begin{array}{l}\text { High-risk examination } \\
\text { features }\end{array}$ \\
\hline $\begin{array}{l}\text { Marfan syndrome or other } \\
\text { connective tissue diseases }\end{array}$ & $\begin{array}{l}\text { Chest, back, or abdominal } \\
\text { pain described as } \\
\text { any of the following: } \\
\text { - abrupt onset } \\
\text { - severe intensity } \\
\text { - ripping or tearing }\end{array}$ & $\begin{array}{l}\text { Evidence of perfusion } \\
\text { deficit: } \\
\text { - pulse deficit } \\
\text { systolic blood pressure } \\
\text { difference } \\
\text { focal neurological deficit } \\
\text { (in conjunction with pain) }\end{array}$ \\
\hline $\begin{array}{l}\text { Family history of aortic } \\
\text { disease }\end{array}$ & $\begin{array}{l}\text { Aortic diastolic murmur } \\
\text { (new and with pain) }\end{array}$ \\
\hline Known aortic valve disease & & Hypotension or shock \\
\hline $\begin{array}{l}\text { Known thoracic aortic } \\
\text { aneurysm }\end{array}$ & & \\
\hline
\end{tabular}

Table 2. Imaging evidences in acute aortic dissection.

\begin{tabular}{|l|}
\hline Aortic Dissection \\
\hline Visualisation of intimal flap \\
\hline Extension of diseases \\
\hline Identification of true or false lumen \\
\hline Localisation of entry an re-entry tears \\
\hline Involvement of the side branches \\
\hline Detection of organ ischemia, pericardial, pleural effusions \\
\hline Detection of peri-aortic bleeding \\
\hline Intramural haematoma \\
\hline Localisation and extent of aortic wall thickening \\
\hline Presence of intimal tear \\
\hline Penetrating aortic ulcer \\
\hline Localisation of the lesion \\
\hline Co-existence of intramural hematoma \\
\hline Involvement of peri-aortic tissue and bleeding \\
\hline
\end{tabular}

CT an MRI have to be considered superior to TOE for the assessment of AAD extension and branch involvement, as well as for the diagnosis of IH, PAU, and traumatic aortic lesions [17].

The sensitivity of TOE reaches $99 \%$, with a specificity of $89 \%$ [19]. The positive and negative predictive values are $89 \%$ and $99 \%$, respectively, based on surgical and/or autopsy data that were independently confirmed [18].

The diagnosis of AAD by standard transthoracic M-mode and twodimensional echocardiography (TTE) is based on detecting intimal flaps in the aorta. The sensitivity and specificity of TTE range from 77 $80 \%$ and $93-96 \%$, respectively, for the involvement of the ascending aorta. The tear is defined as a disruption of flap continuity, with fluttering of the ruptured intimal borders. Smaller intimal tears can be detected by colour Doppler, visualizing jets across the flap, which also identifies the spiral flow pattern within the descending aorta.

TTE is very useful in identifying aortic valve dysfunction, pericardial tamponade, or wall motion abnormalities, and may screen for proximal 4 to $8 \mathrm{~mm}$ of the ascending aorta to just above the sino - tubular junction in patients with good echocardiographic windows and a short segment of the descending aorta in patients with shock. It may show the intimal flap and a thickened aortic wall. The proximal ascending aorta can usually be seen in long- and short-axis parasternal views. TTE is limited, however, in visualizing the distal ascending aorta and the arch. Proximal aortic dilation is usually seen in ascending aortic dissection. The presence of normal aortic dimensions and geometry and absence of aortic regurgitation on TTE are evidence against the presence of an ascending aortic dissection, but this does not fully exclude the diagnosis.

TTE is restricted in patients with abnormal chest wall configuration, narrow intercostal spaces, obesity, pulmonary emphysema, and in patients on mechanical ventilation.

A negative TTE, therefore, does not exclude aortic dissection [18]. To avoid a delay in diagnosis, TTE is not the modality of choice in suspected acute aortic syndrome. Its utility, therefore, in the emergency setting is in the rapid assessment of complications of dissection, such as aortic valve dysfunction, pericardial tamponade, or wall motion abnormalities.

\section{Prognosis}

The risk of death is increased in patients who present with or develop complications of pericardial tamponade, involvement of coronary arteries causing acute myocardial ischaemia/infarction, or malperfusion of the brain [20]

Other predictors of increased in-hospital death include age $\geq 70$ years old, hypotension or cardiac tamponade, kidney failure, and pulse deficits. Less appreciated predisposing factors for Type A dissection include prior cardiac and valvular surgery (15\%) and iatrogenic dissection occurring during cardiac surgery or catheterization (5\%); iatrogenic aortic dissection carries a mortality that is slightly higher than non-iatrogenic (35 vs. 24\%) [21,22].

\section{Conclusion}

Scientific societies advice to utilize a decisional flow chart which rank the risk of the patients to be affected from a AAD. Whether the patient is included in high-risk for referred conditions or pain or examinations features (Table 1) CT scan or TOE must be applied as soon as possible to avoid the delay in the diagnosis. 


\section{References}

1. Tsai TT, Nienaber CA, Eagle KA (2005) Acute aortic syndromes. Circulation 112: 3802-3813. [Crossref]

2. Nienaber CA, Powell JT (2012) Management of acute aortic syndromes. Eur Heart $J$ 33: 26-35b. [Crossref]

3. Olsson C, Thelin S, Stahle E, Ekbom A, Granath F (2006) Thoracic aortic aneurysm and dissection: increasing prevalence and improved outcomes reported in a nation wide population-based study of more than 14,000 cases from 1987 to 2002. Circulation 114: 2611-2618. [Crossref]

4. Howard DP, Banerjee A, Fairhead JF, Perkins J, Silver LE, Rothwell PM (2013) Population based study of incidence and outcome of acute aortic dissection and premorbid risk factor control: 10-year results from the Oxford Vascular Study. Circulation 127: 2031-2037. [Crossref]

5. Hagan PG, Nienaber CA, Isselbacher EM, Bruckman D, Karavite DJ, et al. (2000) The International Registry of Acute Aortic Dissection (IRAD): new insights into an old disease. JAMA 283: 897-903. [Crossref]

6. Januzzi JL, Eagle KA, Cooper JV, Fang J, Sechtem U, et al. (2005) Acute aortic dissection presenting with congestive heart failure: results from the International Registry of Acute Aortic Dissection. J Am Coll Cardiol 46: 733-735. [Crossref]

7. Bonnefoy E, Godon P, Kirkorian G, Chabaud S, Touboul P (2005) Significance of serum troponin I elevation in patients with acute aortic dissection of the ascending aorta. Acta Cardiol 60: 165-170. [Crossref]

8. Gilon D, Mehta RH, Oh JK, Januzzi JL Jr, Bossone E, et al. (2009) Characteristics and in-hospital outcomes of patients with cardiac tamponade complicating type A acute aortic dissection. Am J Cardiol 103: 1029-1031. [Crossref]

9. Di Eusanio M, Trimarchi S, Patel HJ, Hutchison S, Suzuki T, et al. (2013) Clinica presentation, management, and short-term outcome of patients with type A acute dissection complicated by mesenteric malperfusion: observations from the International Registry of Acute Aortic Dissection. J Thorac Cardiovasc Surg 145: 385-390. [Crossref]

10. Richens D, Kotidis K, Neale M, Oakley C, Fails A (2003) Rupture of the aorta following road traffic accidents in the United Kingdom 1992-1999. The results of the co-operative crash injury study. Eur J Cardiothorac Surg 23: 143-148. [Crossref]
11. Moore AG, Eagle KA, Bruckman D, Moon BS, Malouf JF, et al. (2002) Choice of computed tomography, transesophageal echocardiography, magnetic resonance imaging, and aortography in acute aortic dissection: International Registry of Acute Aortic Dissection (IRAD). Am J Cardiol 89: 1235-1238. [Crossref]

12. Moro H, Hayashi J, Sogawa M (1999) Surgical management of the ruptured aortic arch Ann Thorac Surg 67: 593-594. [Crossref]

13. Trimarchi S, Tolenaar JL, Tsai TT, Froehlich J, Pegorer M, et al. (2012) Influence of clinical presentation on the outcome of acute B aortic dissection: evidences from IRAD. J Cardiovasc Surg (Torino) 53: 161-168. [Crossref]

14. Klompas M (2002) Does this patient have an acute thoracic aortic dissection? JAMA 287: 2262-2272. [Crossref]

15. Rogers AM, Hermann LK, Booher AM, Nienaber CA, Williams DM, et al. (2011) Sensitivity of the aortic dissection detection risk score, a novel guideline-based too for identification of acute aortic dissection at initial presentation: results from the international registry of acute aortic dissection. Circulation 123: 2213-2218. [Crossref]

16. Suzuki T, Bossone E, Sawaki D, Jánosi RA, Erbel R, et al. (2013) Biomarkers of aortic diseases. Am Heart J 165: 15-25. [Crossref]

17. Taylor RA, Iyer NS (2013) A decision analysis to determine a testing threshold for computed tomographic angiography and D-dimer in the evaluation of aortic dissection. Am J Emerg Med 31: 1047-1055. [Crossref]

18. Erbel R, Aboyans V, Boileau C, Bossone E, Bartolomeo RD, et al (2014) The Task Force for the Diagnosis and Treatment of Aortic Diseases of the European Society of Cardiology (ESC). Eur Heart J 35: 2873-2926. [Crossref]

19. Gueret P, Senechal C, Roudaut R, Cormier B, Wolf J, Tribouilloy C, et al. (1991) Comparison of transesophageal and transthoracic echocardiography in acute aortic dissection. A multi-center prospective study. J Am Coll Cardiol 17: A260.

20. Suzuki T, Mehta RH, Ince H, Nagai R, Sakomura Y, et al. (2003) Clinical profiles an outcomes of acute type B aortic dissection in the current era: lessons from the International Registry of Aortic Dissection (IRAD). Circulation 108: 11312-11317. [Crossref]

21. Mehta RH, Suzuki T, Hagan PG, Bossone E, Gilon D, et al. (2002) Predicting death in patients with acute type a aortic dissection. Circulation 105: 200-206. [Crossref]

22. Januzzi JL, Sabatine MS, Eagle KA, Evangelista A, Bruckman D, et al. (2002) Iatrogenic aortic dissection. Am J Cardiol 89: 623-626. [Crossref]

Copyright: ( 2017 Lagi A. This is an open-access article distributed under the terms of the Creative Commons Attribution License, which permits unrestricted use, distribution, and reproduction in any medium, provided the original author and source are credited. 